\title{
Food duration and signal-controlled responding by pigeons
}

\author{
DAVID LOPATTO \\ Grinnell College, Grinnell, Iowa \\ and \\ PAUL LEWIS \\ Ohio University, Athens, Ohio
}

\begin{abstract}
Six pigeons were exposed to a procedure in which a tone preceded response-dependent grain. Pecks during the tone omitted grain for that trial. The magnitude of reinforcement, as manipulated by feeder duration, had no effect on the frequency of omission responding. The results are interpreted in the context of Scalar Expectancy Theory.
\end{abstract}

The discovery of autoshaping cast doubt on the belief that the keypeck was an arbitrary operant response (Schwartz, 1981). Because autoshaped keypecks were elicited by the stimulus signaling food, the pecks were relatively unaffected by their consequences. Autoshaped keypecks were acquired and maintained even in circumstances in which the peck omitted food (Williams \& Williams, 1969). If an autoshaping effect occurs in a variety of situations in which signals are correlated with food, then the implication is that many experiments using signaled reinforcement have been confounded by autoshaping. The accurate description of behavior makes it necessary to recognize situations in which autoshaping will occur, and to discover how behavior in signaled-reinforcement studies may resemble autoshaped behavior.

In a previous experiment (Lewis \& Stoyak, 1979), a brief auditory signal paired with keypeck dependent grain led to keypecking during the signal. The pecking was surprisingly strong. When pecks during the signal omitted food for that trial, pecking continued at a high frequency. Either of two stimuli, a clicking sound or a pure tone, could function as the signal. In other experiments, pecking during the signal was due to the pairing of the signal and the reinforcer; presenting the signal in the absence of the reinforcer did not produce pecking during the signal.

Responding during the signal was called "signal-controlled responding" and appears to us to be important for several reasons. First, the signal's control is strong, often resulting in the omission of more than $75 \%$ of potential reinforcers in a session. Second, the procedure is similar to a negative automaintenance procedure (Williams \&

The authors thank Kathy Lopatto for her assistance with graphics. Send reprint requests to D. Lopatto, Department of Psychology, Grinnell College, Grinnell, IA 50112, or to P. Lewis, Psychology Department, Ohio University, Athens, $\mathrm{OH} 45701$.
Williams, 1969). In automaintenance, the stimulus is a keylight; in signal control, the stimulus has been auditory (Lewis \& Stoyak, 1979). The reinforcer is presented independent of behavior during automaintenance, but contingent upon responding during signal control. Omission contingencies affect autoshaped responses and signalcontrolled responses similarly: They reduce but do not eliminate responding (Lewis \& Stoyak, 1979; Williams \& Williams, 1969). Third, the facts that signal control is similar to autoshaping and that the signal control procedure uses common laboratory events (e.g., responsecontingent food) suggest to us that the signal control phenomenon may be involved in a large number of operant experiments, perhaps more so than autoshaping is, because experiments with response-dependent food are more common in operant research than experiments with response-independent food.

To assess the range over which signal-controlled responding occurs and to provide an analogy between the signal control procedure and negative automaintenance, we manipulated food duration. It is typically assumed that operant responses are sensitive to changes in food magnitude (Crespi, 1942). Autoshaped responding, however, is insensitive to changes in food magnitude (Balsam, Brownstein, \& Shull, 1978; Perkins et al., 1975). In autoshaping experiments, food magnitude has been controlled by the duration of presentation of the feeder that holds grain. Thus 4-sec access to grain is a larger reinforcer than 2-sec access to grain. Perkins et al. (1975) presented pigeons with feeder durations of 1,3 , and 9 sec during an autoshaping procedure and found no reliable effect of food magnitude on autoshaping. Balsam et al. (1978) exposed pigeons to feeder durations of 2,4 , and $8 \mathrm{sec}$ during both negative and positive automaintenance and observed no effect of food magnitude on responding. In the present study, we tested feeder durations of 2,8 , and $12 \mathrm{sec}$ in the context of an omission procedure in which a signal preceded response-dependent food. 


\section{METHOD}

\section{Subjects}

Four experimentally naive White Carneaux pigeons, obtained from the Palmetto Pigeon Plant, Sumter, South Carolina, were reduced to $80 \%$ of their free-feeding weights. Fresh water and grit were available in the home cage.

\section{Apparatus}

A standard operant pigeon chamber (Gerbrands) was employed. The chamber measured $31 \mathrm{~cm}$ long, $27 \mathrm{~cm}$ wide, and $32 \mathrm{~cm}$ high. Two response keys and a feeder were located on the front panel of the chamber. The keys were $22 \mathrm{~cm}$ above the floor and were $15 \mathrm{~cm}$ apart. The opening for the feeder was $9 \mathrm{~cm}$ above the chamber floor.

A force of about $0.1 \mathrm{~N}$ was required to press the left key, which could be illuminated by white, red, or green lights. Two white CM 313 lamps mounted near the ceiling provided general illumination, and a similar lamp provided illumination for the feeder when it was operating. Feeder operation provided access to grain. Mounted behind the front panel was a Mallory Sonalert that produced a $2800-\mathrm{Hz}, 70-\mathrm{dB}$ tone. A ventilating fan masked extraneous noise. Electromechanical programming equipment located in an adjacent room provided experimental events and recorded data.

\section{Procedure}

Keypeck training. The left key was continuously illuminated white, and the pigeons were trained to peck it by the method of successive approximations. After keypecking was established, each pigeon was exposed to one session in which 50 4-sec reinforcers were presented. A reinforcer was presented after each peck.

Signal-control procedure. Each daily session consisted of 35 signals delivered on a variable time (VT) 100 -sec schedule. The signal, which lasted $4 \mathrm{sec}$, was a tone generated by the Sonalert. The response key remained white throughout the session. Response-dependent food became available one sec following tone offset, provided that the pigeon did not peck the key during the signal. That is, if the pigeon pecked the key during the tone, food was omitted for the trial and the VT 100sec schedule continued to operate.

Food durations of 2, 8, and $12 \mathrm{sec}$ were studied. Food duration was measured as the time the feeder was available. Pigeons R-1 and R-2 were initially exposed to 2 -sec food presentations. Pigeons R-3 and R-4 were initially exposed to 8-sec food presentations. The order in which the conditions were employed is shown across the top of Figure 1. Pigeons were exposed to each food duration for 20 sessions. In addition, pigeon R-2 was exposed to a condition in which the food that followed the signal was response independent. The food duration was $4 \mathrm{sec}$ during this condition.

\section{RESULTS}

Sessions were divided into signal and control periods. The signal periods were the 4-sec periods when the tone occurred. The control periods were arbitrary 4-sec periods recorded from the beginning of each session, which represented the time when the signal was not on. Control period recordings were interrupted by signal periods and food presentations. The dependent variable was the percentage of signal and control periods in which at least one peck occurred. This measure is referred to as the percent periods with a peck in Figure 1. The dashed lines in Figure 1 represent responding during the signal periods, and the solid lines represent responding during the control periods. The food durations are labeled at the top of the figure.

Each pigeon learned to discriminate between signal and control periods. Few responses occurred while the signal was absent. Pigeons typically pecked during $50 \%$ or more of the tone presentations, which means that the pigeons omitted over half the possible food presentations. Pigeon R-3 omitted nearly all food presentations during the last 20 sessions of the experiment.

The exception to the general consistency of responding occurred when pigeon R-2 was exposed to the signal control procedure with response-independent food following the tone. The data for this condition are shown in Figure 2 , which can be read the same way as Figure 1 .
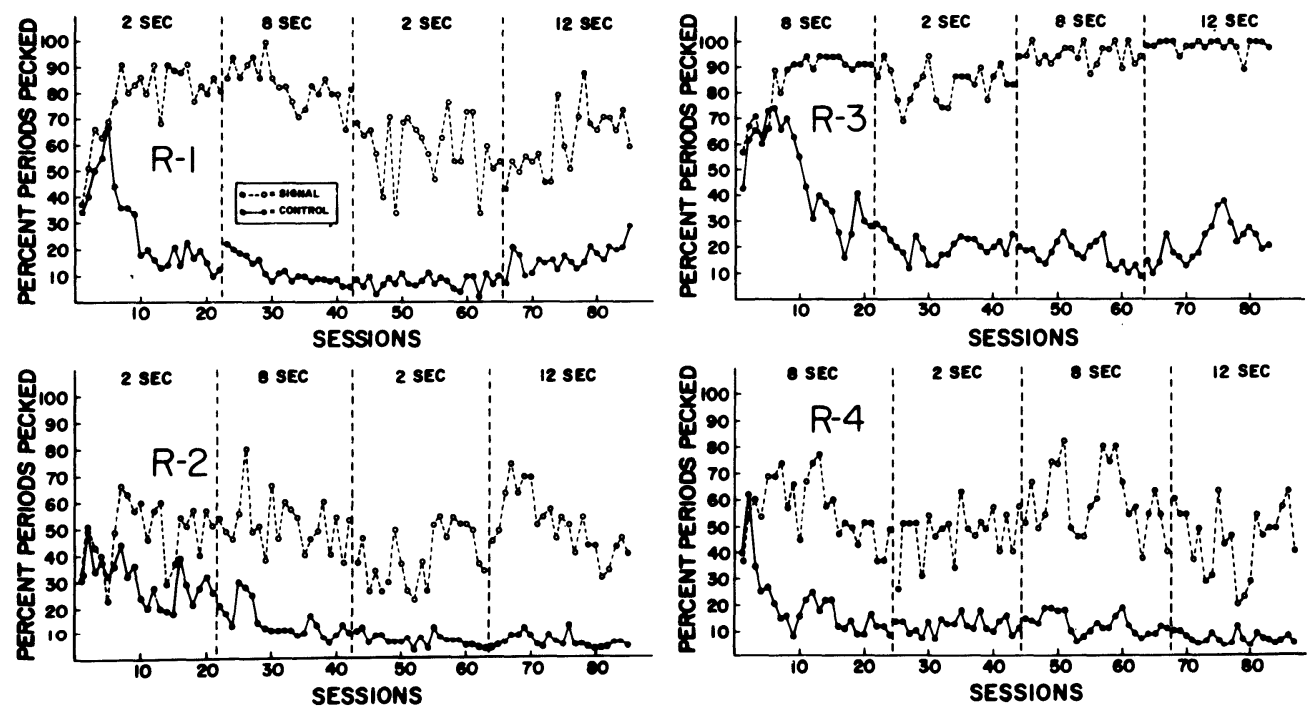

Figure 1. Percent of signal and control periods in which at least one peck occurred. Pecking during the signal periods omitted food. Signal period pecking is represented by dots connected with a dashed line. Control period pecking is represented by dots connected with a solid line. Pigeons pecked more frequently in the signal than in its absence, despite the omission contingency. 


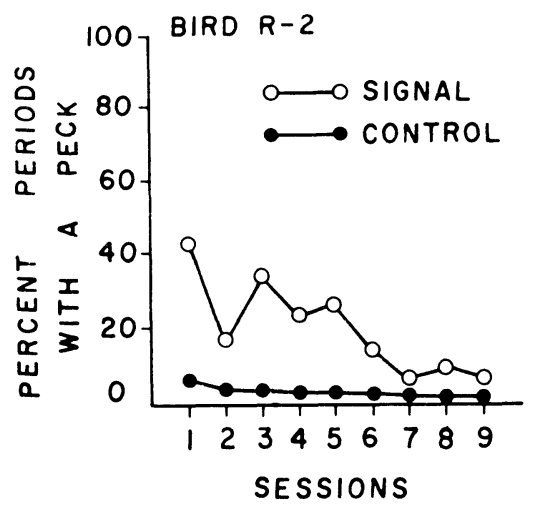

Figure 2. Percent of signal and control periods with a peck for Pigeon R-2 when food following a tone was response independent. Signal period pecking is represented by open circles. Control period pecking is represented by closed circles. The removal of the response contingency resulted in a reduction of signal-controlled responding.

Figure 2 shows that when food following the tone was not dependent on a keypeck, pecking in the signal declined nearly to zero.

There was no effect of food duration; the frequency of omission responses was unaffected by variations in food duration.

\section{DISCUSSION}

The behavior of pigeons exposed to the signal-control procedure resembled the behavior of pigeons exposed to the negative automaintenance procedure (Williams \& Williams, 1969): The pigeons pecked reliably to omit food. In the present case, the pigeons pecked in the presence of a tone. The fact that the tone was an effective omission signal is inconsistent with the results of autoshaping procedures employing a diffuse auditory stimulus (Schwartz, 1973). Pigeons do not autoshape when a diffuse auditory stimulus is paired with response-independent food. A diffuse tone did not maintain responding in the present study (see Figure 2) when the food was response independent. When food was response dependent, however, the tone acted as a discriminative stimulus for responding and acquired such powerful control over pecking that pecks occurred during the tone despite contingent nonreinforcement. In this way the pigeon's behavior during the tone resembled the behavior of pigeons in negative automaintenance.

The failure of food duration to affect pecking in the autoshaping procedure is predicted by Scalar Expectancy Theory (Gibbon \& Balsam, 1981). According to the theory, responding in autoshaping procedures depends on the ratio of the cycle length (the intertrial interval plus the signal) to the signal length. Lengthening the cycle relative to the signal tends to increase pecking; lengthening the signal relative to the cycle tends to decrease pecking. Because the same magnitude of food follows both a cycle and a signal, expectancies about reinforcement are the same in each situation. A change in feeder duration does not influence expectancy differentially in cycle or signal and thus has no effect on responding. Although designed to explain autoshaped behavior, Scalar Expectancy Theory may explain why there was no observable effect of food magnitude in the present signaled reinforcement procedure.

Pecking in the signal-control procedure begins in the manner of a traditional operant response, in which pigeons are trained by the method of successive approximations and maintained by response-dependent food. Yet the pecking of the pigeon in the signal-control procedure resembles the autoshaped keypeck, because the pigeon is relatively insensitive to the consequences of pecking. Signal-controlled pecking may occur in a variety of signaled operant procedures. The presence of signal-controlled pecking may help account for the inconsistency of reinforcement magnitude effects on operant behavior (Neuringer, 1967). Schrier (1958) suggested that the effect of reinforcement magnitude depended on the research design used. If a subject is exposed to one level of reinforcement magnitude in a between-groups design, then a magnitude effect is unlikely; if a subject is exposed to more than one level of magnitude in a within-groups design, then a magnitude effect is likely. In the present case, however, each subject was exposed to all three levels of magnitude, and no effect was observed. Perhaps signal-controlled responding accounts for some of the inconsistent effects of reinforcement magnitude.

\section{REFERENCES}

Balsam, P. D., Brownstein, A. J., \& Shull, R. (1978). Effect of varying the duration of grain presentation on automaintenance. Journal of the Experimental Analysis of Behavior, 29, 27-36.

CRESPI, L. P. (1942). Quantitative variation of incentive and performance in the white rat. American Journal of Psychology, 55, 467-517.

GibBoN, J., \& BALSAM, P. (1981). Spreading association in time. In C. M. Locurto, H. S. Terrace, \& J. Gibbon (Eds.), Autoshaping and Conditioning Theory. New York: Academic Press.

LEWIS, P., \& STOYAK, M. (1979). Signal-controlled responding. Journal of the Experimental Analysis of Behavior, 31, 115-125.

NEURINGER, A. J. (1967). Effects of reinforcement magnitude on choice and rate of responding. Journal of the Experimental Analysis of Behavior, 10, 417-424.

Perkins, C. C., Beavers, W. O., Hancock, R. A., Hemmendinger, P. C., Hemmendinger, D., \& Ricci, J. A. (1975). Some variables affecting rate of key pecking during response-independent procedures (autoshaping). Journal of the Experimental Analysis of Behavior, 24, 59-72.

SCHRIER, A. M. (1958). Comparison of two methods of investigating the effect of amount of reward on performance. Journal of Comparative and Physiological Psychology, 51, 725-731.

SchWARTZ, B. (1973). The role of modality of the signal for food. Journal of the Experimental Analysis of Behavior, 20, 17-22.

SchwarTz, B. (1981). Driving toward a psychology of learning. Contemporary Psychology, 26, 823-825.

Williams, D. R., \& Williams, H. (1969). Automaintenance in the pigeon: sustained pecking despite contingent non-reinforcement. Journal of the Experimental Analysis of Behavior, 12, 511-520.

(Manuscript received for publication March 26, 1985.) 